\title{
Information Technology Integration in Higher Education
}

\author{
A Novel Approach for Impact Assessment \\ http://dx.doi.org/10.3991/ijet.v9i6.4036 \\ Abdulkareem Al-Alwani \\ Yanbu University College (YUC), Yanbu, Saudi Arabia
}

\begin{abstract}
In the current technological world of Information services, academic systems are also in the process of adapting information technology solutions. Information systems vary for different applications and specifically in academia domain, a range of information systems are available for different institutions worldwide. Integration of e-learning can optimize implementation of computer-based and computer-assisted educational processes at all levels. Therefore it is imperative to assess and evaluate integration of these information systems because they have serious impact on elearning processes. In this study an instrument survey is presented for evaluating integration of information technology systems and practices in an educational environment. Survey is constructed using descriptive questions related to information technology tools to assess qualitative impact and usage of such tools. Critical feedback, analysis and suggestions from 25 educationists played a pivotal role in finalizing proposed survey questionnaire. A subsequent test evaluation by teachers and students is also carried out to assess adequate utilization of information systems in Yanbu University College. The results showed that feedback using this survey can help in identifying technological gaps and facilitate effective integration of information technology in an educational environment. Survey instrument proposed in this research can greatly enhance integration of IT tools as it can identify shortcomings by collecting statistical data from feedback of both faculty and students. Solution to these problems is deterministic and can be easily implemented to optimize overall performance of e-learning systems.
\end{abstract}

Index Terms-E-Learning, E-Learning Assessment, Elearning Evaluation

\section{INTRODUCTION}

Integration of information technology is of an important essence for modern educational systems as it acts as an effective tool for delivery of education to its users. Education and research complements technology, which in return provide innovations in learning methods. Information technology has accelerated processes; broaden scope and apt access to education. The usage of information technology (IT), systems and applications have gone through tremendous growth in the last decade [4].

Educational institutions are also in the process of adapting information systems for education purposes. Every field of education is utilizing information systems one way or another. Traditional classrooms are now replaced by virtual ones providing education without teachers. A person sitting in Asia can now learn courses being taught in America. Traditional boards have now upgraded to into digital interactive boards, physical library has been converted to an online library. Information access has become simpler and worldwide.
The importance of information technology calls for an active research to analyze proper integration of information technology in educational systems. Assessing integration of information technology is a difficult task due to its complex nature as it involves evaluation of direct and indirect variables. Another way to assess such systems is to get feedback from users and to analyze how this technology is affecting them. Latter evaluation method is more generic and can be applied to a variety of information technology systems. Based on this trend, various studies have been published on evaluation of information technology and its impact on e-learning systems. Most of these studies have discussed methods to characterize key factors that affect e-learning strategies to achieve an effective online learning environment [3]. Assessment of information technology tools used in these educational processes are seldom evaluated thus their full potential is often not utilize

Relatively few studies have been published on evaluation of information technology systems for e-learning architectures [1][8]. This field of research is not yet fully evolved as information systems provide numerous advantages hindering their optimal capabilities which are insignificant to the user. It is pertinent to mention here, such insignificant functions can improve learning experience of students as presented in this report. Information technology integration in this study is considered as a process encompassing tools and functions. These tools and functions can be used by both students and teachers who are the main clients of the system. A questionnaire based survey is presented in this research to collect statistical data regarding application of IT tools and its frequency of utilization which directly affect student's learning. Tools and functions topology helps in generic classification of any information technology system. This architecture is implemented using this survey instrument and is scalable to cater for a variety of information technology systems that are used in an educational environment.

In the next section, a discussion on pertinent literature to this research is presented. This is followed by a description of the methodology adopted in this research to develop proposed survey instrument. Results and subsequent analysis is presented after taking. This paper is concluded with discussion on prospective advantages of research findings and probable future work that can be pursued based on this research.

\section{LITERATURE REVIEW}

Integration of information technology in any education system requires a careful strategy and execution. Administration thus bears the tremendous responsibility of making sure that integration of information technology in classroom is carefully implemented. This will allow stu- 
PAPER

INFORMATION TECHNOLOGY INTEGRATION IN HIGHER EDUCATION: A NOVEL APPROACH FOR IMPACT ASSESSMENT

dents and teachers to make use of potential benefits offered by information technology systems. In order to evaluate the extent of integration, methods must be pursued which include feedback from main stakeholders using this system; Student and teacher.

A questionnaire based survey to collect response from these users can greatly help in verifying effective IT integration with education systems. Lincoln and Guba [10]; and Creswell [11] mentioned that verification is to be used in demonstrating validity, which helps the researchers in investigating the truth and validity of information discussed. Also, Al-Shammari [2] mentioned in his study that the validity in the research study relates to what this instrument is supposed to measure.

The latest model using survey instrument for IT evaluation is the IS Impact model [6] [7]. This model is most effective in evaluating information systems integration in educational processes as it contained 41 questions spanned over six dimensions:, Information Quality, Use, User Satisfaction, Individual Impact, System Quality, and Organizational Impact [5][7]. Use construct in this model was found unsuitable for measuring successful IS integration. In another research it was reported that information system integration and service quality directly affect mode of use and user satisfaction[8].

Zembylas \& Vrasidas, [9] carried out a research to find the most suitable variables for measuring the success of IT systems in academia. Authors reported that dimensions for evaluation model construct can be reduced to four dimensions as use and quality dimensions can be merged without any significant change in results.

Another important survey instrument called Teachers' Survey Fall 2000 was developed by US Department of Education and Integrated Studies of Education Technology (ISET) [12][13]. First part of this specific survey deals with assessment of IT tools used in classrooms by teachers. Subject authors also requested and received permission to include some questions from the authors of Teachers' survey fall 2000. In general, little research has been done on evaluation of IT systems in an educational environment and is not fully applicable to all IT architectures. This research uses two dimensions which are tools and functions to ascertain quality of IT integration and its effectiveness. Discussion on methodology used to develop survey instrument is presented in the next section explaining implications of using a two dimensional model to assess technology integration in an educational system.

\section{METHODOLOGY}

Methodology followed for development of this instrument survey is segregated in two phases:

- Expert Evaluation of Survey Instrument

- Retrieving Teacher and Student Perspective using Survey Instrument

\section{A. Expert Evaluation of Survey Instrument:}

The survey questions are derived based on the literature review and readings of the researcher conforming them to tools and functions base topology. Tools used in IT must perform some tasks and functions. A software application performance depends on understanding the tool and its appropriate use. Survey instrument is divided into three sections. First section is to be filled by both students and teachers. The Second and the third section are to be filled by teachers and students respectively.

The survey instrument contained 31 questions in the first part, Information Technology Frequency of Use. A total of five options are provided in the first part under 'Hardware/Software Use Frequency'. The options are used to gather statistical data to assess IT usage with relation to computer, word and spreadsheet programs, office application programs, presentation programs, presentation tools, image and drawing programs, multimedia and authoring programs, references, internet browsers, email programs, web page creation programs, lab specific programs, virtual teaching environment programs, real-time collaboration programs, online-based online test generator programs, wiki-based online programs, micro-blogging programs, online mind-mapping programs, web-based dictionary, encyclopedia, visual and audio-rich program, plagiarism detector programs, online admin source for administrator, social platform for faculty and students, and online translator.

In the second part, there are two question categories. There are 22 questions for teachers and 15 questions for students. . Again five options for both set of questions are used as a measure for 'Objectives of Use'. Questions in these categories measure the 'Objective of IT Use' by assessing ability of a user to apply IT systems in various applications to improve educational technology activities. The section containing questions for teachers is developed to assess their ability to gather information for planning lessons, accessing model lesson plans, accessing information and research, creating multimedia presentations, creating quizzes, record-keeping, communication with colleagues, posting homework, posting and sharing student's work on the web and LMS, learning and improving computer skills, detecting plagiarism, authoring online curriculum, engaging in real-time collaboration, helping students for discussion and debate, making online multimedia documents, improving on teaching-learning skills and strategies, and participating in online meeting and brainstorm sessions. Similar topology is followed for the questionnaire developed for the students.

To obtain an expert vetting from experts educationists, an email invitation was forwarded to more 100 educationists in various universities to participate in the survey. Survey instrument is constructed using base architecture of tools and function topology and is subsequently improved using feedback from respondents. The respondents included teachers from different fields and academic experiences. The participants are instructed to respond whether the items that are designed in - IT Frequency of Use and Objective for Use are clear or not clear (clarity) or whether they are related to the heading (title) of the survey instrument. The author received 25 responses who responded to the survey. Out of the 25, 22 are males and 8 are females. However, all participants remained anonymous. Based on experts scores for Clarity and Relevance, some items of the survey were deleted, adjusted, and added

\section{B. Teacher and Student Feedback using Survey Instrument:}

Survey instrument was finalized after expert evaluation and feedback. Next phase included testing survey on an IT based E-Learning system. 8 teachers and 40 students were selected and were given this survey to record their response. survey is given to 40 students in 2 nd semester. 
Survey is again given to same group of students in the next two semesters consecutively. Similarly, survey was repeatedly given to 2 nd semester teachers to record their opinion. Feedback from students and teachers will provide two main advantages. Firstly, authors will be able to find shortcomings in the Integration of IT, and secondly they will be able to follow improvements by users in e-learning systems based on their recommendations. Recommendations may include trainings, tutorials, group discussion and assignments etc to optimize use of IT systems and applications.

\section{RESULTS}

Purpose of this study is to assess the impact of IT in education systems. Using the methodology described above, the whole process of evaluation is distributed in 2 phases. In first phase, survey is improved and finalized after expert evaluation. Table-I and Table-II through Table-VI shows percentage scores given for 'CLARITY' and 'RELATION TO TITLE' to the questions included in the survey. This phase helped in building authors confidence that relevant questions are added which can identify how IT is being used and for what purpose.

After $1^{\text {st }}$ phase, testing is tantamount to validate this instrument survey. 40 students from $1^{\text {st }}$ semester are selected to record their responses. Teachers for this class were also approached to record their feedback. For students, the same procedure is followed for the next two semesters recording feedback from the same group of 40 students. Feedback from teachers is also taken for three consecutive semesters. As the main purpose of this research is to analyze the impact of information technology for education and learning, results gathered from students are presented in Table-VII and Table-VIII.

Feedback from first semester allowed for gathering important statistics to identify shortcomings among the students. Based on these indicators, trainings and seminars were conducted to improve students exposure to information technology systems and processes. For, example in Table-VII students showed progress with each successive semester and improved in applying IT to different processes and applications as shown in Table-VIII. Initial feedback from 1st semester students provided information on obstructions and problems in using specific IT tools and functions. Students were divided into groups based on their orientation towards information technology. Learning material is then modified to improve ability of each group in using IT tools. As information technology includes a lot of tools and functions, questionnaire was intentionally developed to include questions related to prospective tools and functions that are used during high level education and are described in the methodology section. It was much easier to bring teachers on the same grid as students as teachers were found to be more coherent with existing IT tools and functions. For the same reason feedback from students is discussed as they provide the best measure to evaluate impact of Information Technology in their learning.
A. Frequency of Use.

TABLE I.

PERCENTAGE AND FREQUENCY FOR 'ClARITY OF ITEM’

\begin{tabular}{|l|c|c|}
\hline \multicolumn{1}{|c|}{ Items } & Percentage & Frequency \\
\hline $1,2,6$ & $100 \%$ & 3 \\
\hline $\begin{array}{l}3,7,8,9,10,11,12,13,14,15,16,17,18, \\
19,22,23,24,25,26,27,28,29,30,31\end{array}$ & $88 \%$ & 24 \\
\hline 20,21 & $84 \%$ & 2 \\
\hline 4,5 & $72 \%$ & 2 \\
\hline
\end{tabular}

TABLE II

Percentage and FrequenCy for 'Relation to Sub-Title’

\begin{tabular}{|l|c|c|}
\hline \multicolumn{1}{|c|}{ Items } & Percentage & Frequency \\
\hline $\begin{array}{l}1,2,3,7,9,10,13,14,15,16,19,27,28, \\
29,30,31\end{array}$ & $96 \%$ & 16 \\
\hline $8,11,12,23,24,25,26$, & $92 \%$ & 7 \\
\hline $5,6,17,20,21$, & $84 \%$ & 5 \\
\hline $4,18,22$ & $80 \%$ & 3 \\
\hline
\end{tabular}

B. Objective of Use (Teacher Section)

TABLE III.

PERCENTAGE AND FREQUENCY FOR 'CLARITY OF ITEM’

\begin{tabular}{|l|c|c|}
\hline \multicolumn{1}{|c|}{ Items } & Percentage & Frequency \\
\hline 1 & $96 \%$ & 1 \\
\hline $9,10,11,12,13,14,15,16,19,21,22,24$ & $92 \%$ & 12 \\
\hline $2,3,4,5,17,18,20,21,25$ & $88 \%$ & 9 \\
\hline 23 & $76 \%$ & 1 \\
\hline
\end{tabular}

TABLE IV

Percentage and FReQuenCy For 'Relation to Sub-TitLE'

\begin{tabular}{|l|c|c|}
\hline \multicolumn{1}{|c|}{ Items } & Percentage & Frequency \\
\hline 1 & $100 \%$ & 1 \\
\hline $2,3,4,5,11,15,9,17$ & $96 \%$ & 8 \\
\hline 7,8, & $92 \%$ & 2 \\
\hline $10,12,13,14,16,21,22$ & $88 \%$ & 7 \\
\hline 18,19 & $84 \%$ & 2 \\
\hline 6,20 & $76 \%$ & 2 \\
\hline
\end{tabular}

C. Objective of Use (Student Section)

TABLE $\mathrm{V}$.

PERCENTAGE AND FREQUENCY FOR 'ClARITY OF ITEM’

\begin{tabular}{|l|c|c|}
\hline \multicolumn{1}{|c|}{ Items } & Percentage & Frequency \\
\hline $1,2,3,4$ & $92 \%$ & 4 \\
\hline $6,9,10,12,13$ & $90 \%$ & 5 \\
\hline $5,7,8,11$ & $88 \%$ & 4 \\
\hline
\end{tabular}

TABLE VI.

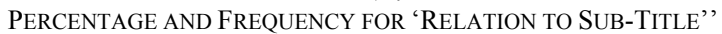

\begin{tabular}{|l|c|c|}
\hline \multicolumn{1}{|c|}{ Items } & Percentage & Frequency \\
\hline $1,2,4,5,6,8,11,12,13$ & $98 \%$ & 9 \\
\hline $3,7,9,10$ & $96 \%$ & 4 \\
\hline
\end{tabular}


TABLE VII.

CONSECUTIVE FEEDBACK By STUDENTS OVER 2 SEMESTER FOR 'FREQUENCY OF USE'

\begin{tabular}{|c|c|c|c|c|c|c|c|c|c|c|}
\hline \multirow{3}{*}{$\begin{array}{l}\stackrel{0}{Z} \\
\Xi \\
\stackrel{\Xi}{\Xi}\end{array}$} & \multicolumn{10}{|c|}{ Hardware/Software Use Frequency } \\
\hline & \multicolumn{2}{|c|}{$\begin{array}{l}\dot{B} \\
\dot{0} \\
\dot{0} \\
\dot{0}\end{array}$} & \multicolumn{2}{|c|}{ 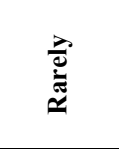 } & \multicolumn{2}{|c|}{ 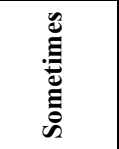 } & \multicolumn{2}{|c|}{ 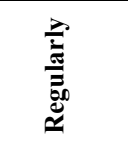 } & \multicolumn{2}{|c|}{ 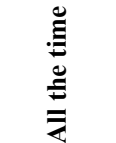 } \\
\hline & $1 s t$ & $2 n d$ & $1 s t$ & $2 n d$ & 1st & $2 n d$ & $1 s t$ & $2 n d$ & $1 s t$ & 2nd \\
\hline A.1 & 1 & 0 & 8 & 6 & 11 & 15 & 12 & 11 & 8 & 8 \\
\hline A. 2 & 2 & 1 & 12 & 8 & 10 & 13 & 10 & 9 & 6 & 9 \\
\hline A.3 & 5 & 2 & 11 & 6 & 8 & 12 & 9 & 14 & 7 & 6 \\
\hline A. 4 & 4 & 1 & 16 & 10 & 9 & 15 & 10 & 13 & 1 & 1 \\
\hline A. 5 & 6 & 2 & 12 & 7 & 7 & 9 & 8 & 10 & 7 & 12 \\
\hline A. 6 & 8 & 3 & 12 & 8 & 7 & 11 & 9 & 8 & 4 & 10 \\
\hline A.7 & 3 & 1 & 11 & 5 & 6 & 12 & 15 & 16 & 5 & 6 \\
\hline A. 8 & 7 & 1 & 10 & 6 & 9 & 14 & 8 & 15 & 6 & 4 \\
\hline A. 9 & 9 & 2 & 14 & 10 & 5 & 7 & 8 & 18 & 4 & 3 \\
\hline A.10 & 12 & 3 & 6 & 2 & 12 & 16 & 7 & 14 & 3 & 5 \\
\hline A.11 & 8 & 2 & 11 & 7 & 8 & 13 & 7 & 14 & 6 & 4 \\
\hline A. 12 & 4 & 2 & 11 & 3 & 8 & 12 & 11 & 16 & 6 & 7 \\
\hline A.13 & 7 & 4 & 14 & 8 & 9 & 10 & 8 & 15 & 2 & 3 \\
\hline A.14 & 4 & 2 & 18 & 9 & 5 & 7 & 6 & 12 & 7 & 10 \\
\hline A. 15 & 11 & 5 & 19 & 12 & 3 & 5 & 6 & 13 & 1 & 5 \\
\hline A.16 & 9 & 6 & 14 & 11 & 9 & 11 & 4 & 8 & 4 & 4 \\
\hline A. 17 & 5 & 2 & 8 & 5 & 12 & 13 & 12 & 12 & 3 & 8 \\
\hline A. 18 & 6 & 4 & 9 & 6 & 16 & 19 & 8 & 7 & 1 & 4 \\
\hline A.19 & 8 & 5 & 17 & 12 & 7 & 12 & 4 & 6 & 4 & 5 \\
\hline A. 20 & 9 & 2 & 13 & 7 & 4 & 16 & 9 & 10 & 5 & 5 \\
\hline A. 21 & 5 & 2 & 16 & 10 & 9 & 11 & 6 & 13 & 4 & 4 \\
\hline A. 22 & 11 & 8 & 16 & 7 & 7 & 9 & 4 & 8 & 2 & 8 \\
\hline A. 23 & 4 & 2 & 18 & 12 & 6 & 10 & 7 & 10 & 5 & 6 \\
\hline A. 24 & 9 & 3 & 12 & 5 & 9 & 13 & 8 & 12 & 2 & 7 \\
\hline A. 25 & 9 & 4 & 14 & 9 & 10 & 14 & 7 & 10 & 0 & 3 \\
\hline A.26 & 14 & 7 & 16 & 4 & 3 & 9 & 5 & 16 & 2 & 4 \\
\hline A. 27 & 8 & 3 & 12 & 6 & 14 & 18 & 4 & 7 & 2 & 6 \\
\hline A. 28 & 13 & 8 & 10 & 8 & 5 & 7 & 7 & 11 & 5 & 6 \\
\hline A.29 & 18 & 10 & 13 & 9 & 6 & 9 & 3 & 8 & 0 & 4 \\
\hline A. 30 & 24 & 12 & 11 & 7 & 2 & 6 & 3 & 12 & 0 & 3 \\
\hline A.31 & 21 & 11 & 13 & 6 & 4 & 6 & 2 & 10 & 0 & 7 \\
\hline
\end{tabular}

As it can be seen from the tables above that student in the $1^{\text {st }}$ semester were at varying stages for usage and applicability of IT systems. After providing students with training along with detailed lectures on tools and applications, progressive improvement was shown by students as per feedback for the next semester. Results showed significant improvement in student's orientation towards ITS applications. Thus integration of information technology in an education system can be assessed and improved using proposed survey which provides a tool/function based metric to evaluate IT integration and usage. These results were collected over a span of two semesters and they show student's tendency to learn and apply IT tools and functions.

\section{CONCLUSION}

This research study is carried out to articulate a survey instrument for assessing integration of Information Tech-
TABLE VIII.

CONSECUTIVE FEEDBACK BY STUDENTS OVER 2 SEMESTER FOR 'OBJECTIVE OF USE'

\begin{tabular}{|c|c|c|c|c|c|c|c|c|c|c|}
\hline \multirow{3}{*}{$\begin{array}{l}\stackrel{ }{Z} \\
\stackrel{\Xi}{\Xi}\end{array}$} & \multicolumn{10}{|c|}{ Ability to Use } \\
\hline & \multicolumn{2}{|c|}{ ż } & \multicolumn{2}{|c|}{ 预 } & \multicolumn{2}{|c|}{ 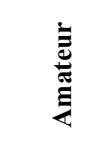 } & \multicolumn{2}{|c|}{ } & \multicolumn{2}{|c|}{ 音 } \\
\hline & 1st & 2nd & 1st & 2nd & 1st & 2nd & 1st & 2nd & 1st & 2nd \\
\hline C.b.1 & 5 & 2 & 11 & 6 & 8 & 12 & 9 & 14 & 7 & 6 \\
\hline C.b.2 & 4 & 1 & 16 & 10 & 9 & 15 & 10 & 13 & 1 & 1 \\
\hline C.b.3 & 6 & 2 & 12 & 7 & 7 & 9 & 8 & 10 & 7 & 12 \\
\hline C.b.4 & 9 & 2 & 14 & 10 & 5 & 7 & 8 & 18 & 4 & 3 \\
\hline C.b.5 & 12 & 3 & 6 & 2 & 12 & 16 & 7 & 14 & 3 & 5 \\
\hline C.b.6 & 8 & 2 & 11 & 7 & 8 & 13 & 7 & 14 & 6 & 4 \\
\hline C.b. 7 & 4 & 2 & 11 & 3 & 8 & 12 & 11 & 16 & 6 & 7 \\
\hline C.b. 8 & 9 & 6 & 14 & 11 & 9 & 11 & 4 & 8 & 4 & 4 \\
\hline C.b. 9 & 5 & 2 & 8 & 5 & 12 & 13 & 12 & 12 & 3 & 8 \\
\hline C.b.10 & 6 & 4 & 9 & 6 & 16 & 19 & 8 & 7 & 1 & 4 \\
\hline C.b.11 & 8 & 5 & 17 & 12 & 7 & 12 & 4 & 6 & 4 & 5 \\
\hline C.b.12 & 21 & 11 & 13 & 6 & 4 & 6 & 2 & 10 & 0 & 7 \\
\hline C.b.13 & 4 & 2 & 18 & 12 & 6 & 10 & 7 & 10 & 5 & 6 \\
\hline C.b.14 & 7 & 4 & 14 & 8 & 9 & 10 & 8 & 15 & 2 & 3 \\
\hline C.b.15 & 4 & 2 & 18 & 9 & 5 & 7 & 6 & 12 & 7 & 10 \\
\hline
\end{tabular}

nology in education systems. Initially, an expert evaluation approach is followed which greatly enhances the validity of proposed survey instrument. After evaluation from experts, survey was presented for feedback to 40 fresh students. Based on initial feedback, students are split into three groups based on their understanding of the IT tools and functions. Coursework is then slightly adjusted to include IT oriented material in the first 2 semester to improve their knowledge and competence in IT tools and applications. Results showed response of students on ITS integration and therefore apt integration of ITS in an educational environment can be confirmed based on their feedback.

Student's feedback is collected for two consecutive semesters to assess efficacy of information technology. Shortcoming in IT usage and applications are identified based on feedback of students.. Results showed that students feedback can be used as a metric to evaluate integration of information technology; furthermore this survey can also envelopes student's ability to use and apply IT tools Same procedure is followed for teachers with an aim to understand their skills in using IT systems and applications. It was found out that almost all teachers are acquainted with prevailing IT tools and functions and are in no need for any specific training. Still in a case where teachers are found lagging behind, this survey can again help in understanding exact requirements that can help teachers

After detailed feedback and subsequent analysis authors suggest three basic advantage which offered by this survey instrument

- Integration of Information Technology can be evaluated

- Problem areas can be identified pertaining to IT 'Tools' and 'Functions'

- Specific trainings/courses can be organized to educate students on most relevant IT tools and functions 
PAPER

INFORMATION TECHNOLOGY INTEGRATION IN HIGHER EDUCATION: A NOVEL APPROACH FOR IMPACT ASSESSMENT

Overall, these results demonstrate the importance of feedback to evaluate IT systems integration in educational processes. Not only such methods allow room for improvement for students and teachers but also in assessing improper or proper usage of IT tools. And in the current technological era, lagging behind in optimized integration of IT systems can seriously affect academic learning. For future research it is recommended to apply proposed methodology for larger systems as basic theme lies in 'Tools' and 'Functions' topology which makes proposed research scalable to include as many tools and functions as required. Proposed approach can be improvised to integrate and apply IT functions effectively on a large scale educational environment via detailed evaluation.

\section{REFERENCES}

[1] Aceto, S., Delrio, C., Dondi, C., Fischer, T., Kastis, N., Klein, R., et al. (2007). e-Learning for Innovation: Executive Summary of the Helios Yearly Report 2007e-Learning for Innovation: Executive Summary of the Helios Yearly Report 2007. Brussels: MENON Network EEIG.

[2] Al-Shammari, Z. (2005). Special education teachers' attitudes toward autistic students in the Autism School in the State of $\mathrm{Ku}$ wait: A case study. The Journal of Instructional Psychology. Vol. (32), No. (3).

[3] Alshehri, A. (2005). Assessing faculty attitudes toward the significant factors for facilitating the implementation of online courses at the Institute of Public Administration in Saudi Arabia. Mississippi State University

[4] Berger, A. N. (2003), The economic effects of technological progress: evidence from the banking industry, Journal of Money, Credit, Banking, 35 (2), 141-176 http://dx.doi.org/10.1353/ mcb.2003.0009

[5] Cao, Lan \& Elias, Nur Fazidah (2009) Validating the IS-Impact model: Two exploratory case studies in China and Malaysia. InBapna, Ravi \& Sambamurthy, V (Eds.) Proceedings of the Pacific Asia Conference on Information Systems 2009, Association for In- formation Systems (AIS), Hotel Novotel, Hyderabad, India, pp. 114.

[6] Gable G, Sedera D And Chan T (2003) Enterprise systems success: a measurement model. In Proceedings of the Twenty-Fourth International Conference on Information Systems (MARCH S, MASSEY A and DEGROSS JI, Eds), p. 576, Association for Information Systems, Seattle, Washington, US.

[7] Gable, G., Sedera, D., \& Chan, T. (2008). Re-conceptualizing information system success : the IS-Impact Measurement Model. Journal of the Association for Information Systems, 9(7), 377-408

[8] Wang, Y., Wang, H., \& Shee, D. (2007). Measuring e-learning systems success in an organizational context: Scale development and validation. Computers in Human Behavior, 23(4), 1792-1808. http://dx.doi.org/10.1016/j.chb.2005.10.006

[9] Zembylas, M., \& Vrasidas, C. (2007). Listening for silence in textbased, online encounters. Distance Education, 28(1), 5-24 http://dx.doi.org/10.1080/01587910701305285

[10] Lincoln, Y. S., \& Guba (1985). Naturalistic inquiry. Beverly Hills, CA: Sage.

[11] Creswell, J. W. (1998). Qualitative inquiry and research design: Choosing among five traditions. Thousand Oaks, CA: SAGE.

[12] U.S. Department of Education. (2003) Federal funding for educational technology and how it is used in the classroom: A summary of findings from the integrated studies of educational technology. Retrieved from http://www.ed.gov/rschstat/eval/tech/iset/sum mary2003.pdf

[13] U. S. Department of Education. (2000). eLearning: Putting a world-class education at the fingertips of all children. Washington, DC: U.S. Department of Education,Office of Educational Technology. http://www.ed.gov/Technology/elearning/e-learning.pdf

\section{AUTHOR}

Abdulkareem Al-Alwani is with the College of Computer Science \& Engineering, Yanbu University College (YUC), Yanbu, Saudi Arabia.

Submitted 13 July 2014. Published as resubmitted by the authors 08 December 2014 